\title{
Regioselective Synthesis of Bromo-Substituted 3-Arylcoumarins
}

\author{
Maria João Matos, ${ }^{* a}$ Giovanna Delogu, ${ }^{\mathrm{b}}$ Gianni Podda, ${ }^{\mathrm{b}}$ Lourdes Santana, ${ }^{\mathrm{a}}$ Eugenio Uriarte ${ }^{\mathrm{a}}$ \\ a Departamento de Química Orgánica, Facultad de Farmacia, Universidad de Santiago de Compostela, 15782 Santiago de Compostela, \\ Spain \\ Fax +34(981)594912; E-mail: mariacmatos@gmail.com \\ b Dipartimento Farmaco Chimico Tecnologico, Università degli Studi di Cagliari, 09124 Cagliari, Italy \\ Received 4 March 2010; revised 6 May 2010
}

\begin{abstract}
Regioselective syntheses of 3-arylcoumarins possessing a bromine substituent either on the 3-aryl ring, the coumarin moiety or on a lateral chain of a coumarin is reported. The regioselectivity is influenced by the substituents present in the substrates. Two different bromination methods are described and compared. Perkin condensation of 5-methylsalicylaldehyde and phenylacetic acid or para-methoxyphenylacetic acid affords the desired coumarins. Three different bromine substitution patterns are accessed starting from 5-methylsalicylaldehyde.
\end{abstract}

Key words: natural products, halogenation, bromine, regioselectivity, coumarins

Phenylcoumarins are synthetic compounds in which an additional phenyl ring is present as a substituent at any position on the coumarin nucleus. They are easily prepared using two general methods: 1) coumarin phenylation, ${ }^{1}$ or 2) via construction of the coumarin nucleus with the aryl ring already in place, e.g., by way of Perkin, ${ }^{2}$ Pechmann, ${ }^{3,4}$ Mukaiyama, $^{5}$ Knoevenagel $^{6}$ or PerkinOglialoro $^{7}$ reactions. In the present work we utilize the second method, and specifically the classical Perkin condensation. ${ }^{8}$ This represents a direct and general method for preparing 3-phenylcoumarins.

A number of natural products and synthetic analogues featuring the coumarin structural motif display a broad spectrum of biological activity. ${ }^{9}$ Structurally, 3-phenylcoumarins can be considered as coumarin-resveratrol hybrids (Figure 1); these are very important molecular frameworks and are synthetically versatile. ${ }^{10}$ The C3-C4 double bond of the coumarin nucleus fixes the trans disposition of the $t$-resveratrol-type double bond. ${ }^{3}$ The interesting pharmacological properties of trans-resveratrol has led to increased interest in synthetic studies toward its analogues. ${ }^{3,10}$<smiles>O=c1oc2c(O)cc(O)cc2cc1-c1ccc(O)cc1</smiles>

Figure 1 6,8-Dihydroxy-3-(4'-hydroxyphenyl)coumarin (a coumarin-resveratrol hybrid)

SYNTHESIS 2010, No. x, pp 000A-000D

Advanced online publication: Xx.xx.2010

DOI: 10.1055/s-0029-1218835; Art ID: T05010SS

(c) Georg Thieme Verlag Stuttgart · New York
Halogenation of aromatic and heteroaromatic compounds is an important reaction in synthetic organic chemistry. ${ }^{11}$ Aryl and heteroaryl bromides are potential antioxidant, antibacterial and antitumor agents. ${ }^{12}$ They also represent interesting precursors to many substituted analogues. Hence, bromination reactions are versatile and have been studied extensively. Brominating agents such as tetraalkylammonium tribromide, ${ }^{13}$ 1,8-diazabicyclo[5.4.0] undec-7ene hydrobromide perbromide $\left(\mathrm{DBUHBr}_{3}\right),{ }^{14}$ hexamethylenetetramine tribromide ${ }^{15}$ and $N$-bromosuccinimide (NBS) $)^{16,17}$ are known to facilitate monobromination of aromatic compounds and their derivatives. However, as a result of its ready availability and ease of handling, the latter reagent is the most commonly used brominating agent. The use of $N$-bromosuccinimide in the solid state, ${ }^{18}$ or in traditional solution reactions, enables efficient monobromination of aromatics and derivatives such as coumarins. ${ }^{19,20} \mathrm{~N}$-Bromosuccinimide has been used for bromination and/or oxidation reactions..$^{21-24}$ It is also used for the conversion of benzaldehydes into the corresponding benzoyl bromides and for bromolactonization of unsaturated acids and their derivatives. ${ }^{25-27}$ Mild reaction conditions, good yields, and simple, rapid reactions are some of the advantages of using $N$-bromosuccinimide. It has been reported that bromination of coumarins occurs mainly at C-3, leading to the corresponding monobromo derivatives. ${ }^{17}$ In the present compounds this position is blocked by a phenyl ring leading to a change in the reactivity of the coumarin. Side-chain bromination in benzyl or allylic systems can be mediated by free radical initiators, while aromatic bromination requires a catalyst. ${ }^{28}$ Electron-rich aromatic compounds are easily brominated using $N$-bromosuccinimide. ${ }^{18}$ Several studies on regioselective bromination of coumarins have been performed with the aim of synthesizing bioactive natural products. $^{29,30}$

As part of our research on 3-arylcoumarins, we previously reported the synthesis of 6-methyl-3-arylcoumarins with the aryl ring being mono- (compound 2), di- or tri-methoxy-substituted. ${ }^{10}$ The 3-phenylcoumarins demonstrated important roles in monoamine oxidase (MAO) enzymatic inhibition. ${ }^{10} \mathrm{We}$ found that the presence of a methoxy group on the 3-phenyl ring was important, especially a para-methoxy group, in order to improve the monoamine oxidase inhibitor (MAOI) activity.

In this paper, we report the direct and selective synthesis of various bromo-substituted 6-alkyl-3-arylcoumarins. 
The bromine atom can be installed on the 3-phenyl ring (compound 3) or on the aromatic ring of the coumarin (compound 5). In addition, conditions which allow the bromine atom to be substituted on a lateral chain (compound 7) are described.

3-Arylcoumarins with different substitution patterns were prepared via a direct synthetic route involving the classical Perkin procedure. ${ }^{8,10,31-33}$ The reactions were accomplished by condensation of appropriately substituted salicylaldehydes with phenylacetic or $p$-methoxyphenylacetic acids, using $N, N^{\prime}$-dicyclohexylcarbodiimide (DCC) as the dehydrating agent, in dimethyl sulfoxide, at $110^{\circ} \mathrm{C}$ for 24 hours (Scheme 1)..$^{8,31,32}$ Coumarins $2^{10}$ and 5 were obtained in yields of $61 \%$ and $50 \%$, respectively, by reaction of salicylaldehydes 1 and $\mathbf{4}^{8,31,32}$ with $p$-methoxyphenylacetic acid.

Treatment of 6-methyl-3-(4'-methoxyphenyl)coumarin (2) with $\mathrm{N}$-bromosuccinimide, at reflux in carbon tetrachloride, using 2,2'-azobis(isobutyronitrile) (AIBN) as the catalyst, afforded brominated phenylcoumarin $\mathbf{3}$ in a yield of $41 \%$. The regioselective formation of $\mathbf{3}$ occurred as a result of activation of the ortho position in substrate 2 by the electron-donating methoxy group. Under these conditions, the 6-methyl group was not sufficiently activating to direct bromination onto the coumarin moiety.

3-Bromo-2-hydroxy-5-methylbenzaldehyde (4), ${ }^{31-33}$ the brominated precursor of coumarin $\mathbf{5}$, was prepared from $\mathbf{1}$ in $44 \%$ yield, using the same brominating conditions as described above (Scheme 1). The ortho position relative to the hydroxy substituent, and meta to the aldehyde, was the most active, and as such was the position at which bromination occurred.

5-Bromomethyl-2-hydroxybenzaldehyde (6) was obtained in 34\% yield via irradiation of precursor 1 and bromine in carbon tetrachloride using a tungsten light source. The ability to brominate salicylaldehyde $\mathbf{1}$, regioselectively, enabled the synthesis of 3-arylcoumarins 5 (from 4) and 7 (from 6), via the classical Perkin condensation, in $50 \%$ and $60 \%$ yields, respectively. Thus, bromination of 1 using different reaction conditions allowed the position of the bromine atom in the final coumarin product to be varied.

It is interesting to note that with compounds $\mathbf{1}$ and $\mathbf{2}$, which both possess benzylic protons, treatment with $\mathrm{N}$ bromosuccinimide using conditions (b) did not afford the corresponding bromomethyl derivatives. These substrates contain a strong electron-donating group, and hence aromatic substitution occurs instead of benzylic substitution.

On the other hand, unsubsituted 3-phenylcoumarin ${ }^{34}$ was prepared and then treated with $\mathrm{N}$-bromosuccinimide using the above-mentioned conditions, however, no bromo derivative was obtained. The absence of an activating substituent prevents the electrophilic aromatic substitution occurring. Thus, in a substrate without strong activating groups, the presence of an alkyl substituent could lead to benzylic halogenation instead of aromatic substitution.

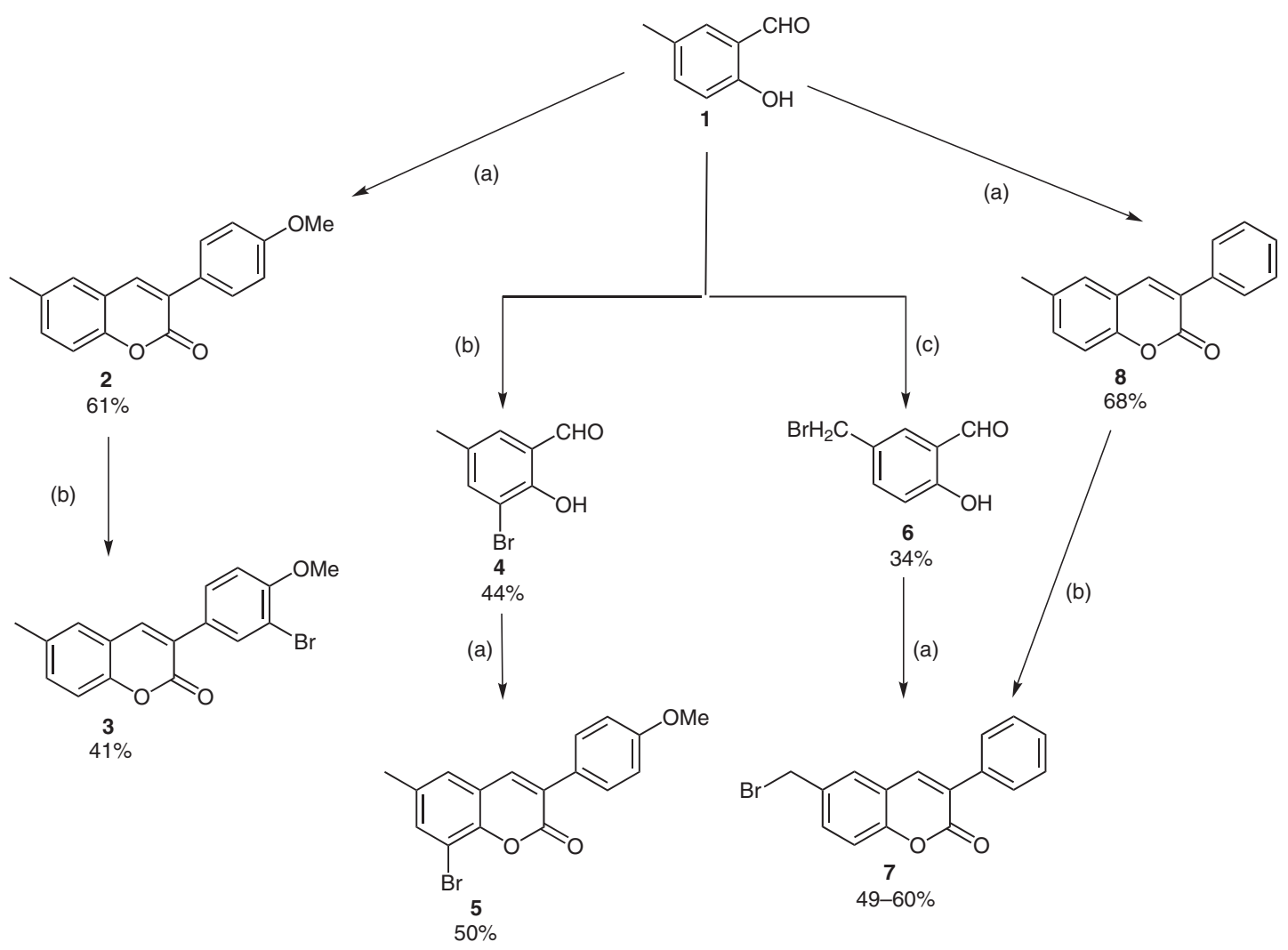

Scheme 1 Reagents and conditions: (a) phenylacetic acid or $p$-methoxyphenylacetic acid (1.25 equiv), DCC (1.56 equiv), DMSO, $110^{\circ} \mathrm{C}, 24$ h; (b) NBS (1.2 equiv), AIBN (cat.), $\mathrm{CCl}_{4}$, reflux, $18 \mathrm{~h}$; (c) $\mathrm{Br}_{2}$ (1.4 equiv), tungsten light source, $\mathrm{CCl}_{4}, 8 \mathrm{~h}$. 
6-Methyl-3-phenylcoumarin (8) ${ }^{10}$ with no substituent on the 3-phenyl ring, was reacted under the same brominating conditions to afford 6-bromomethyl-3-phenylcoumarin (7) in a yield of $49 \%$ (Scheme 1). In this case, with no sufficiently strong activating group for aromatic bromination, the bromine atom was instead directed to the lateral chain. This reaction sequence represents another method to obtain bromoalkylcoumarin 7 .

Comparing the formation of arylcoumarins $\mathbf{3}$ and $\mathbf{7}$ from 6-methyl-3-arylcoumarins $\mathbf{2}$ and $\mathbf{8}$, respectively, the presence of a methoxy group results in bromination on the 3aryl ring, whilst the absence of a methoxy group leads to bromine substitution on the lateral chain. Introduction of a bromine atom on the coumarin ring is possible by aromatic bromination of the precursor salicylaldehyde. In this specific case, the hydroxy substituent on the benzene ring directs substitution of the bromine atom at the appropriate position.

In conclusion, convenient procedures have been developed starting from the 5-methylsalicylaldehyde (1), that enable bromination on the aryl, methyl or coumarin moieties in differently substituted arylcoumarins. The 3-arylcoumarin products can be used as precursors for other molecules and for pharmacological evaluation.

Melting points were obtained using a Reichert Kofler Thermophan or in capillary tubes with a Büchi 510 apparatus and are uncorrected. ${ }^{13} \mathrm{C}(75 \mathrm{MHz})$ and ${ }^{1} \mathrm{H} \mathrm{NMR}(300 \mathrm{MHz})$ spectra were recorded on a Bruker AMX $300 \mathrm{MHz}$ spectrometer. Chemical shifts $(\delta, J$ in $\mathrm{Hz})$ are reported in ppm relative to TMS as the internal standard. Mass spectra were obtained using a Hewlett-Packard 5988A spectrometer. Elemental analyses were recorded on a Perkin-Elmer 240B microanalyzer. Silica gel (Merck 60, 230-400 mesh) was used for flash chromatography. Analytical TLC was performed on plates precoated with silica gel (Merck 60 F254, $0.25 \mathrm{~mm}$ ).

\section{3-(3'-Bromo-4'-methoxyphenyl)-6-methylcoumarin (3)}

A soln of 6-methyl-3-(4'-methoxyphenyl)coumarin (2) (1.0 g, 3.76 $\mathrm{mmol})$, NBS $(0.80 \mathrm{~g}, 4.51 \mathrm{mmol})$ and AIBN (cat.) in $\mathrm{CCl}_{4}(5.0 \mathrm{~mL})$ was stirred under reflux for $18 \mathrm{~h}$. The resulting soln was filtered to remove succinimide. The solvent was evaporated under vacuum and purified by flash chromatography (hexane-EtOAc, 95:5) to give compound $\mathbf{3}$.

White solid; yield: 41\%; mp 206-207 ${ }^{\circ} \mathrm{C}$.

${ }^{1} \mathrm{H} \mathrm{NMR}\left(\mathrm{CDCl}_{3}\right): \delta=2.42\left(\mathrm{~s}, 3 \mathrm{H}, \mathrm{CH}_{3}\right), 3.94\left(\mathrm{~s}, 3 \mathrm{H}, \mathrm{OCH}_{3}\right), 6.97$ (d, $\left.J=8.7 \mathrm{~Hz}, 1 \mathrm{H}, \mathrm{H}-5^{\prime}\right), 7.23-7.35$ (m, $\left.3 \mathrm{H}, \mathrm{H}-2^{\prime}, \mathrm{H}-6^{\prime}, \mathrm{H}-5\right)$, 7.69-7.74 (m, 2 H, H-7, H-8), 7.89 (s, $1 \mathrm{H}, \mathrm{H}-4$ ).

${ }^{13} \mathrm{C} \mathrm{NMR}\left(\mathrm{CDCl}_{3}\right): \delta=20.8,56.3,111.5,111.6,116.1,119.3$, 126.3, 127.6, 128.5, 129.0, 132.5, 133.1, 134.2, 139.1, 151.5, 156.2, 160.6 .

MS (EI): $m / z(\%)=347(18), 346(98), 345(19), 344(100)\left[\mathrm{M}^{+}\right]$, 303 (45), 301 (45), 275 (11), 250 (17), 222 (13), 194 (11), 178 (13), 165 (58), 163 (11), 139 (15), 132 (42), 82 (18), 76 (14), 63 (19), 50 (14).

Anal. Calcd for $\mathrm{C}_{17} \mathrm{H}_{13} \mathrm{BrO}_{3}: \mathrm{C}, 59.15 ; \mathrm{H}, 3.80$. Found: C, 59.10; H, 3.71 .

8-Bromo-3-(4'-methoxyphenyl)-6-methylcoumarin (5)

A soln of 3-bromo-2-hydroxy-5-methylbenzaldehyde (4) (0.25 g, $1.16 \mathrm{mmol}), p$-methoxyphenylacetic acid $(0.24 \mathrm{~g}, 1.45 \mathrm{mmol})$ and
DCC $(0.37 \mathrm{~g}, 1.81 \mathrm{mmol})$, in DMSO $(2.0 \mathrm{~mL})$, was heated at $100-$ $110{ }^{\circ} \mathrm{C}$ in an oil bath for $24 \mathrm{~h}$. Ice $(20 \mathrm{~g})$ and $\mathrm{AcOH}(3.0 \mathrm{~mL})$ were added and the mixture was stirred at r.t. for $2 \mathrm{~h}$, and then extracted with $\mathrm{Et}_{2} \mathrm{O}(3 \times 25 \mathrm{~mL})$. The combined organic layer was washed with $5 \%$ aq $\mathrm{NaHCO}_{3}$ soln $(50 \mathrm{~mL})$ and $\mathrm{H}_{2} \mathrm{O}(20 \mathrm{~mL})$, and dried $\left(\mathrm{Na}_{2} \mathrm{SO}_{4}\right)$. The solvent was evaporated under vacuum and the residue was purified by flash chromatography (hexane-EtOAc, 9:1) to give coumarin $\mathbf{5}$.

White solid; yield: 50\%; mp 144-145 ${ }^{\circ} \mathrm{C}$.

${ }^{1} \mathrm{H} \mathrm{NMR}\left(\mathrm{CDCl}_{3}\right): \delta=2.41\left(\mathrm{~s}, 3 \mathrm{H}, \mathrm{CH}_{3}\right), 3.86\left(\mathrm{~s}, 3 \mathrm{H}, \mathrm{OCH}_{3}\right), 6.98$ $\left(\mathrm{d}, J=7.1 \mathrm{~Hz}, 2 \mathrm{H}, \mathrm{H}-3^{\prime}, \mathrm{H}-5^{\prime}\right), 7.26$ (s, $\left.1 \mathrm{H}, \mathrm{H}-7\right), 7.56$ (s, $1 \mathrm{H}, \mathrm{H}-$ 5), 7.65-7.69 (m, $3 \mathrm{H}, \mathrm{H}-2^{\prime}, \mathrm{H}-6$ ', H-4).

${ }^{13} \mathrm{C}$ NMR $\left(\mathrm{CDCl}_{3}\right): \delta=20.5,55.4,109.3,114.0,120.7,126.7$, $126.9,128.5,129.9,135.2,137.8,148.1,159.9,160.3$.

MS (EI): $m / z(\%)=346(99), 345(15), 344(100)\left[\mathrm{M}^{+}\right], 303$ (53), 301 (54), 275 (15), 207 (15), 166 (17), 165 (72), 138 (17), 89 (13), $76(14), 58$ (41).

Anal. Calcd for $\mathrm{C}_{17} \mathrm{H}_{13} \mathrm{BrO}_{3}$ : C, 59.15; H, 3.80. Found: C, 59.27; H, 3.82 .

\section{5-Bromomethylsalicylaldehyde (6)}

To a soln of 5-methylsalicylaldehyde (1) $(2.0 \mathrm{~g}, 14.69 \mathrm{mmol})$ in $\mathrm{CCl}_{4}(23.0 \mathrm{~mL})$, under reflux and with tungsten light irradiation (300 W, Philips Reflector R125 35 ), was added $\mathrm{Br}_{2}$ ( $3.29 \mathrm{~g}, 20.57$ $\mathrm{mmol}$ ) over a period of $3 \mathrm{~h}$. The soln was stirred at r.t. for a further $15 \mathrm{~h}$ and the resulting precipitate was filtered and washed with $\mathrm{CCl}_{4}$ to give aldehyde 6.

White solid; yield: $34 \%$; mp $148^{\circ} \mathrm{C}$.

${ }^{1} \mathrm{H} \mathrm{NMR}\left(\mathrm{CDCl}_{3}\right): \delta=4.43\left(\mathrm{~s}, 2 \mathrm{H}, \mathrm{CH}_{2}\right), 6.96(\mathrm{~d}, J=8.4 \mathrm{~Hz}, 1 \mathrm{H}$, H-3), 7.49-7.53 (m, 2 H, H-4, H-6), 9.88 (s, 1 H, CHO), 10.21 (s, 1 $\mathrm{H}, \mathrm{OH})$.

${ }^{13} \mathrm{C}$ NMR $\left(\mathrm{CDCl}_{3}\right): \delta=33.2,115.2,128.4,130.9,131.0,136.4$, 162.0, 191.4 .

MS (EI): $m / z(\%)=216(14), 215(61), 214(100)\left[\mathrm{M}^{+}\right], 184$ (17), 168 (12), 121 (15), 17 (10).

Anal. Calcd for $\mathrm{C}_{8} \mathrm{H}_{7} \mathrm{BrO}_{2}$ : C, 44.68; H, 3.28. Found: C, 44.66; H, 3.23 .

\section{6-Bromomethyl-3-phenylcoumarin (7)}

Coumarin 7 was obtained in $60 \%$ yield starting from 5-bromomethylsalicylaldehyde (6), according to the procedure described for the synthesis of compound $\mathbf{5}$. The same product was also obtained in $49 \%$ yield starting from coumarin $\mathbf{8}$ using an identical method to that described for the preparation of $\mathbf{3}$.

White solid; mp $174-175{ }^{\circ} \mathrm{C}$.

${ }^{1} \mathrm{H}$ NMR $\left(\mathrm{CDCl}_{3}\right): \delta=4.56\left(\mathrm{~s}, 2 \mathrm{H}, \mathrm{CH}_{2}\right), 7.34-7.72\left(\mathrm{~m}, 8 \mathrm{H}, \mathrm{H}-2^{\prime}\right.$, H-3', H-4', H-5', H-6', H-5, H-7, H-8), 7.79 (s, 1 H, H-4).

${ }^{13} \mathrm{C}$ NMR $\left(\mathrm{CDCl}_{3}\right): \delta=32.1,117.0,119.7,128.2,128.5,128.9$, 129.0, 132.0, 134.3, 134.4, 139.2, 153.1, 160.2.

MS (EI): $m / z(\%)=315(23), 314$ (100), 179 (21), 176 (40), 152 (12), 118 (19), 89 (15), 76 (16).

Anal. Calcd for $\mathrm{C}_{16} \mathrm{H}_{11} \mathrm{BrO}_{2}$ : C, 60.98; H, 3.52. Found: C, 60.89; H, 3.47 .

\section{Acknowledgment}

The authors thank the Spanish Ministry (PI061457 and P509/ 00501) and Xunta da Galicia (PXIB20304PR) for financial support. M.J.M. thanks Fundação de Ciência e Tecnologia for the SFRH/ BD/61262/2009 scholarship. 


\section{References}

(1) Chen, G.; Tokunaga, N.; Hayashi, T. Org. Lett. 2005, 7, 2285.

(2) Perkin, W. H. J. Chem. Soc. 1868, 21, 53.

(3) Vilar, S.; Quezada, E.; Santana, L.; Uriarte, E.; Yánez, M.; Fraiz, N.; Alcaide, C.; Cano, E.; Orallo, F. Bioorg. Med. Chem. Lett. 2006, 16, 257.

(4) Santana, L.; González-Díaz, H.; Quezada, E.; Uriarte, E.; Yáñez, M.; Viña, D.; Orallo, F. J. Med. Chem. 2008, 51, 6740.

(5) Mukaiyama, T. Angew. Chem., Int. Ed. Engl. 1979, 18, 707.

(6) Bogdal, D. J. Chem. Res., Synop. 1998, 468.

(7) Bakhchinian, R.; Terrier, F.; Kirkiacharian, S.; RescheRigon, M.; Bouchoux, F.; Cerede, E. Farmaco 2003, 58, 1201.

(8) Hans, N.; Singhi, M.; Sharma, V.; Grover, S. K. Indian J. Chem., Sect. B: Org. Chem. Incl. Med. Chem. 1996, 35, 1159.

(9) Borges, F.; Roleira, F.; Milhazes, N.; Santana, L.; Uriarte, E. Curr. Med. Chem. 2005, 12, 887.

(10) Matos, M. J.; Viña, D.; Quezada, E.; Picciau, C.; Delogu, G.; Orallo, F.; Santana, L.; Uriarte, E. Bioorg. Med. Chem. Lett. 2009, 19, 3268.

(11) Larock, R. C. Comprehensive Organic Transformations: A Guide to Functional Group Preparations; Wiley-VCH: New York, 1997.

(12) Butler, A.; Walker, J. V. Chem. Rev. 1993, 93, 1937.

(13) Kajigaeshi, S.; Kakinami, T.; Okamoto, T.; Nakamura, H.; Fujikama, M. Bull. Chem. Soc. Jpn. 1987, 60, 4187.

(14) Muathen, H. A. J. Org. Chem. 1992, 57, 2740.

(15) Bisarya, S. C.; Rao, R. Synth. Commun. 1993, 23, 779.

(16) Konishi, H.; Aritomi, K.; Okano, T.; Kiji, J. Bull. Chem. Soc. Jpn. 1989, 62, 591.
(17) Das, B.; Venkateswarlu, K.; Krishnaiah, M.; Holla, H. Tetrahedron Lett. 2006, 47, 8693.

(18) Sarma, J. A. R. P.; Nagaraju, A.; Majumdar, K. K.; Samuel, P. M.; Das, I.; Roy, S.; McGhie, A. J. J. Chem. Soc., Perkin Trans. 2 2000, 1119.

(19) Xiao, S.; Yi, T.; Li, F.; Huang, C. Tetrahedron Lett. 2005, $46,9009$.

(20) Xie, L.; Yu, D.; Wild, C.; Allaway, G.; Turpin, J.; Smith, P. C.; Lee, K.-H. J. Med. Chem. 2004, 47, 756.

(21) Organic Solid State Chemistry; Desiraju, G. R., Ed.; Elsevier: Amsterdam, 1987.

(22) Seebach, D. Angew. Chem., Int. Ed. Engl. 1990, 29, 1320.

(23) Goud, B. S.; Desiraju, G. R. J. Chem. Res., Synop. 1995, 244.

(24) Sarma, J. A.; Nagaraju, A. J. Chem. Soc., Perkin Trans. 2 2000, 1113.

(25) Cheung, Y.-F. Tetrahedron Lett. 1979, 20, 3809.

(26) Pearson, A. J.; Ray, T. Tetrahedron Lett. 1986, 27, 111.

(27) Dai, W.; Katzenellenbogen, J. A. J. Org. Chem. 1991, 56, 6893.

(28) Schmid, H. Helv. Chim. Acta 1946, 29, 1144.

(29) Maes, D.; Vervisch, S.; Debenedetti, S.; Davio, C.; Mangelinckx, S.; Giubellina, N.; De Kimpe, N. Tetrahedron 2005, 61, 2505.

(30) Riveiro, M. E.; Maes, D. Bioorg. Med. Chem. 2009, 17, 6547.

(31) Mohanty, S.; Makrandi, J. K.; Grover, S. K. Indian J. Chem., Sect. B: Org. Chem. Incl. Med. Chem. 1989, 28, 766.

(32) Kamat, S. P.; D'Souza, A. M.; Paknikar, S. K.; Beauchamp, P. S. J. Chem. Res., Synop. 2002, 242.

(33) Adams, R. J. Am. Chem. Soc. 1919, 41, 247.

(34) Wang, L.; Jing, H.; Bu, X.; Chang, T.; Jin, L.; Liang, Y. Catal. Commun. 2007, 8, 80. 